\title{
Combining sitagliptin/metformin with a functional fiber delays diabetes progression in Zucker rats
}

\author{
Raylene A Reimer ${ }^{1,2}$, Gary J Grover ${ }^{3,4}$, Lee Koetzner ${ }^{3}$, Roland J Gahler ${ }^{5}$, \\ Michael R Lyon ${ }^{6,7}$ and Simon Wood ${ }^{5,7}$ \\ ${ }^{1}$ Faculty of Kinesiology and ${ }^{2}$ Department of Biochemistry and Molecular Biology, Faculty of Medicine, University \\ of Calgary, 2500 University Drive Northwest, Calgary, Alberta, Canada T2N 1N4 \\ ${ }^{3}$ Product Safety Labs, Department of Pharmacology, Dayton, New Jersey, USA \\ ${ }^{4}$ Department of Physiology and Biophysics, Robert Wood Johnson Medical School, Piscataway, New Jersey, USA \\ ${ }^{5}$ Factors Group of Nutritional Companies, Inc. R\&D, 3655 Bonneville Place, Burnaby, British Columbia, Canada \\ ${ }^{6}$ Canadian Centre for Functional Medicine, 1552 United Boulevard, Coquitlam, British Columbia, Canada \\ ${ }^{7}$ University of British Columbia, Food, Nutrition and Health Program, Vancouver, British Columbia, Canada
}

Correspondence should be addressed to R A Reimer

Email

reimer@ucalgary.ca

\begin{abstract}
Our primary objective was to determine whether administering the viscous and fermentable polysaccharide PolyGlycopleX (PGX) with metformin (MET) or sitagliptin/metformin (S/MET) reduces hyperglycemia in Zucker diabetic fatty (ZDF) rats more so than monotherapy of each. Glucose tolerance, adiposity, satiety hormones and mechanisms related to dipeptidyl peptidase 4 activity, gut microbiota and, hepatic and pancreatic histology were examined. Male ZDF rats (9-10 weeks of age) were randomized to: i) cellulose/vehicle (control, C); ii) PGX (5\% wt/wt)/vehicle (PGX); iii) cellulose/metformin (200 mg/kg) (MET); iv) cellulose/S/MET (10 mg/kg + $200 \mathrm{mg} / \mathrm{kg})(\mathrm{S} / \mathrm{MET}) ; \mathrm{v})$ PGX (5\%) + MET (200 mg/kg) (PGX+MET); vi) cellulose/sitagliptin/MET $(5 \%)+(10 \mathrm{mg} / \mathrm{kg}+200 \mathrm{mg} / \mathrm{kg})(\mathrm{PGX}+\mathrm{S} / \mathrm{MET})$ for 6 weeks. $\mathrm{PGX}+\mathrm{MET}$ and $\mathrm{PGX}+\mathrm{S} / \mathrm{MET}$ reduced glycemia compared with $\mathrm{C}$ and singular treatments $(P=0.001)$. Weekly fasted and fed blood glucose levels were lower in PGX+MET and $\mathrm{PGX}+\mathrm{S} / \mathrm{MET}$ compared with all other groups at weeks 4,5 , and $6(P=0.001)$. HbA1c was lower in $\mathrm{PGX}+\mathrm{S} / \mathrm{MET}$ than $\mathrm{C}, \mathrm{MET}, \mathrm{S} / \mathrm{MET}$, and PGX at week $6(P=0.001)$. Fat mass was lower and GLP1 was higher in PGX + S/MET compared with all other groups $(P=0.001)$. $\beta$-cell mass was highest and islet degeneration lowest in PGX+S/MET. Hepatic lipidosis was significantly lower in PGX+S/MET compared with PGX or S/MET alone. When combined with PGX, both MET and S/MET markedly reduce glycemia; however, PGX + S/MET appears advantageous over PGX + MET in terms of increased $\beta$-cell mass and reduced adiposity. Both combination treatments attenuated diabetes in the obese Zucker rat.
\end{abstract}
Key Words
- PolyGlycopleX
- DPP4 inhibitor
- obesity
- diabetes medication
- glycemia

Journal of Endocrinology

(2014) 220, 361-373

\section{Introduction}

Obesity is a well-recognized risk factor for the development of type 2 diabetes (Daousi et al. 2006). As the prevalence of obesity continues to escalate worldwide, so too has the prevalence of diabetes (Franco et al. 2013). A 73 and 20\% increase in diabetes numbers is expected to occur in developing and developed countries, respectively, before 2030 (Shaw et al. 2010). Effective management of disease progression in these individuals will require 
strategies that target multiple facets of metabolism and should include combined lifestyle and pharmacological therapy (National Institutes of Health 1998). Using a targeted approach to identify dietary factors that augment specific actions of proven pharmacological agents holds promise for slowing the progression of diabetes in overweight and obese individuals.

Metformin (MET) is a first-line antihyperglycemic agent that is widely prescribed for the management of type 2 diabetes (Scheen \& Paquot 2013). Sitagliptin is a newer antidiabetic agent that increases circulating levels of active glucagon-like peptide 1 (GLP1) by inhibiting dipeptidyl peptidase 4 (DPP4) activity (Ahren 2007). Given that treatment with single antihyperglycemic agents often fails to achieve adequate glycemic control in patients with type 2 diabetes, combinations of medications are often required (Inzucchi 2002). Indeed, sitagliptin has already been approved for use in combination with MET and is marketed under the trade name Janumet (Aschner et al. 2006, Charbonnel et al. 2006). Several clinical trials have evaluated the combination of sitagliptin plus MET (reviewed in St Onge et al. (2012)) and demonstrated consistent HbA1c lowering and fewer hypoglycemic episodes compared with MET combined with other agents such as glipizide (Nauck et al. 2007).

The dietary factors that contribute to the effective management of type 2 diabetes are numerous and include a variety of dietary fibers that reduce hypercholesterolemia and hyperglycemia, enhance satiety, and improve bowel function depending on the fiber examined (Weickert \& Pfeiffer 2008). In general, viscous dietary fibers reduce glycemia to a greater extent than non-viscous fibers (Chutkan et al. 2012). PolyGlycopleX ( $\alpha$-D-glucurono- $\alpha$-D-manno- $\beta$-D-manno- $\beta$-D-gluco), $(\alpha-\mathrm{L}$-gulurono- $\beta$-D mannurono), $\beta$-D-gluco- $\beta$-D-mannan (PGX) is a highly viscous and fermentable functional fiber that has been shown to reduce hyperglycemia and increase GLP1 secretion in obese Zucker rats (Grover et al. 2011b). We have recently demonstrated that the individual glycemialowering potential of sitagliptin and PGX can be augmented when they are co-administered in obese Zucker rats (Reimer et al. 2012a). Whether the effectiveness of MET and sitagliptin/metformin (S/MET) can likewise be improved with co-administration with PGX is not known.

Our objective was to determine if the antihyperglycemic actions of MET and S/MET are enhanced when administered with PGX in obese Zucker rats. Mechanisms related to changes in adiposity, satiety hormone secretion, gut permeability and microbiota, pancreatic islet survival, and DPP4 activity were examined. We hypothesize that the combined treatment of PGX with S/MET will result in lower glycemia than PGX, MET, or S/MET administered alone.

\section{Materials and methods}

\section{Rats and treatments}

Ethical approval for the experimental protocol was granted by the Product Safety Labs Institutional Animal Use and Care Committee. All procedures conformed to the Guide for Care and Use of Laboratory Animals. Sixty six male Zucker diabetic fatty rats (ZDF)/Crl-Leprfa/fa rats were obtained from Charles River (Kingston, NY, USA) at 7-8 week of age and individually housed in a temperature $\left(19-22^{\circ} \mathrm{C}\right)$ and humidity-controlled $(50-79 \%)$ room with a $12 \mathrm{~h}$ light: $12 \mathrm{~h}$ darkness cycle. Water and feed were provided ad libitum. Following 12 days of acclimation, rats were randomly assigned to one of six groups ( $n=11 /$ group): i) cellulose/vehicle (control, C); ii) PGX $(5 \%$ wt/wt)/vehicle (PGX); iii) cellulose/metformin (200 mg/kg) (MET); iv) cellulose/S/MET (10 mg/kg + $200 \mathrm{mg} / \mathrm{kg})$ (S/MET); v) PGX (5\%)+MET $(200 \mathrm{mg} / \mathrm{kg})$ (PGX+MET); vi) PGX/S/MET (5\%) + (10 mg/kg + $200 \mathrm{mg} / \mathrm{kg})$ $(\mathrm{PGX}+\mathrm{S} / \mathrm{MET})$. The drugs were administered for 6 weeks. The dose of PGX has been shown to reduce HbA1c and serum cholesterol and increase $\beta$-cell mass previously (Grover et al. 2011b, Reimer et al. 2012a). Doses of MET and sitagliptin were selected from the low end of the ranges used in the literature (Chen et al. 2011, Maiztegui et al. 2011, Pyra et al. 2012) in order that potential synergistic effects with PGX could be detected. Administration of MET or S/MET was via oral gavage given on a daily basis in the morning. The composition of the diets which were formulated on a background diet of $24 \%$ fat $(\mathrm{wt} / \mathrm{wt})$ and containing the test fiber, PGX, or the insoluble reference fiber, cellulose (Anderson et al. 1994), has been previously published (Reimer et al. 2012a). MET and S/MET hydrochloride (as Janumet) were obtained by prescription at a pharmacy in Dayton, NJ and prepared in water for the daily gavage.

\section{Weekly measures}

Body weight was measured weekly and food intake three times per week. Blood glucose was measured consistently once each week in the fasted (overnight $16 \mathrm{~h}$ ) and fed state using a Bayer Ascensia Elite Glucometer (Bayer Health Care).

Published by Bioscientifica Ltd. 


\section{Oral glucose tolerance tests}

Three days before the end of the study, an oral glucose tolerance test (OGTT) was performed with $1 \mathrm{~g} / \mathrm{kg}$ glucose and blood sampling via tail nick at $0,10,20,30,60$, and $120 \mathrm{~min}$. Blood glucose and serum insulin concentrations were measured. A second and separate OGTT with $2 \mathrm{~g} / \mathrm{kg}$ glucose load was performed for satiety hormone analysis at the end of the study. Blood was collected at $0,15,30,60$, and $90 \mathrm{~min}$ via tail nick into chilled tubes containing diprotinin-A $(0.034 \mathrm{~g} / 1$ blood; MP Biomedicals, Irvine, CA, USA), Sigma protease inhibitor $(1 \mathrm{~g} / 1$ blood; Sigma Aldrich), and Roche Pefabloc ( $1 \mathrm{~g} / \mathrm{l}$ blood; Roche). Plasma was stored at $-80^{\circ} \mathrm{C}$ until later analysis. The composite insulin sensitivity index (CISI), where higher scores represent improved insulin sensitivity, was calculated (Grover et al. 2011b).

\section{Cholesterol, DPP4 activity, and clinical chemistry}

On the final day of the study, following an overnight fast and regular drug treatment, rats were over-anesthetized with isoflurane and a cardiac blood sample collected. Total cholesterol concentration was measured in the blood using an automated analyzer (Polymer Technology Systems, CardioChek, PA, USA). Plasma DPP4 activity was measured according to Kirino et al. (2009). A clinical chemistry panel was analyzed in serum and included: blood urea nitrogen, glucose, electrolytes, creatinine, alkaline phosphatase, aspartate aminotransferase (ALT), alanine aminotransferase (AST), and bilirubin.

\section{Body composition}

At the end of the study, lean mass, fat mass, and bone mineral content were assessed using dual energy X-ray absorptiometry (Hologic ODR 4500, Hologic, Bedford, MA, USA).

\section{Tissue collection and histology}

Following the cardiac blood draw, one kidney, one lobe of the liver, and a section of the distal ileum were snapfrozen for later DPP4 analysis (DPP4 activity in kidney and Dpp4 mRNA levels according to our previous work (Reimer et al. 2012a)). The pancreas was fixed in 10\% neutral buffered formalin and transferred to $70 \%$ ethanol after $24 \mathrm{~h}$. The pancreas was serial sectioned twice at approximately five microns and either stained with hematoxylin and eosin or immunohistochemically stained with a mouse antibody against rat insulin according to our previous work (Grover et al. 2011a). The percent islet area containing insulin-positive cells was determined by morphometric evaluation using the Image-Pro Plus (IPP) software system. Ten to twelve randomly selected islets representing areas throughout the pancreas per animal were measured for insulin-positive and insulin-negative areas under $20 \times$ objective magnification and the percentage of the insulin immunopositive determined. All other findings were determined by semi-quantitative scoring of morphologic changes by a veterinary pathologist, where the following scoring matrix applied: $0=$ within normal limits; $1=$ minimal; $2=$ mild; $3=$ moderate; $4=$ marked; and $5=$ severe. One lobe of the liver was fixed in $10 \%$ formalin and following processing and embedding was sectioned $(5 \mu \mathrm{m})$ and stained with hematoxylin and eosin. One liver lobe was snap-frozen for the determination of lipid content with Sudan Black staining. Histopathology scoring was the same as described earlier for the pancreas.

\section{Regulators of feeding behavior and HbA1c}

A Rat Gut Hormone Multiplex Kit (Millipore, Billerica, MA, USA) was used to measure active GLP1, active ghrelin, total PYY, and total GIP according to our previous work (Eller \& Reimer 2010, Pyra et al. 2012, Reimer et al. 2012a). Insulin was measured with a rat insulin ELISA (Millipore). HbA1c was measured in blood using a clinical analyzer (Bayer DCA 2000).

\section{Gut microbiota analysis}

Microbial profiling was performed according to our previous work (Bomhof et al. 2013). Briefly, total bacterial DNA was extracted from cecal samples using FastDNA Spin Kit for Feces (MP Biomedicals, Lachine, QC, Canada). Amplification and detection were conducted in 96-well plates with SYBR Green $2 \times$ qPCR Master Mix (Bio-Rad). The 16S rRNA gene copies value was calculated according the following webpage: http://cels.uri.edu/gsc/cndna. html using average genome sizes. Standard curves were normalized to the copy number of the 16S rRNA gene obtained from the following webpage: http://rrndb.mmg. msu.edu/index.php.

\section{Markers of intestinal permeability}

Concentrations of plasma LPS from the terminal cardiac blood sample was measured using a PyroGene Recombinant Factor C Endotoxin Endpoint Fluorescent Detection assay (Lonza, Basel, Switzerland) according to

Published by Bioscientifica Ltd. 
manufacturer directions. Expression of the tight junctionassociated genes, zona occludens-1 (ZO1) and occludin, as well as proglucagon was analyzed according to our standard real-time PCR protocol (Bomhof et al. 2013). Actin was used as the housekeeping gene and data analyzed with the $2^{-\Delta C t}$ method.

\section{Statistical analyses}

All data are presented as mean \pm s.E.M. A two-way ANOVA was used to determine the main effects of diet (PGX vs cellulose) and drug (MET vs S/MET vs vehicle) and their interaction. When a significant interaction effect was identified (indicating that the influence of the diet on the outcome of interest was dependent on the presence of the drug or vice versa), a one-way ANOVA with Tukey's multiple comparison post hoc test was used to assess the differences between the individual groups. For parameters where repeated measurements were taken over time (i.e., body weight, glucose, HbA1c, and satiety hormones), a two-way repeated measure ANOVA was performed with between subject factor (six treatment groups) and within subject factor (time). Significance was set at $P<0.05$.

\section{Results}

\section{Food intake and body weight}

Food intake was lower in all groups compared with $\mathrm{C}$ (Table 1). Furthermore, rats fed PGX, alone, or in combination with MET or S/MET, had lower intake than $\mathrm{C}$, MET, and S/MET. Over the 6 week intervention, rats treated with PGX + S/MET maintained the lowest body weight that was significantly different from all other groups at week 5 and significantly different from all other groups except PGX + MET at weeks 2, 3, 4, 6, and 7
$(P=0.001$; Fig. 1A). The interaction between diet and drug affected fat mass $(P=0.001)$ wherein $P G X+S / M E T$ was lower than all other groups and MET was higher than S/MET and PGX + MET. There were no differences in lean mass between groups.

\section{Glycemic response}

Rats treated with PGX + MET and PGX + S/MET consistently had the lowest blood glucose concentrations (Fig. 1B). Already at week 2, the combination treatments had lower glucose concentrations than $\mathrm{C}$ and the singular treatments $(P<0.001)$. While hyperglycemia was exacerbated with time in C, MET, S/MET, and PGX rats, glycemia in PGX + MET and PGX + S/MET rats did not increase and at week 6 remained significantly lower than all other groups $(P<0.02)$. Blood glucose was also measured in the fed state on a weekly basis (Fig. 1C). By week 3, all treatments had lower blood glucose concentrations than $\mathrm{C}$ $(P=0.001)$ with PGX, PGX + MET, and PGX + S/MET also lower than S/MET. By 6 weeks, PGX + MET and PGX+ S/MET had significantly lower glucose than all other groups $(P<0.002)$, while PGX was lower than MET, S/MET, and C $(P=0.001)$. Similarly, HbA1c was affected by the interaction of time and treatment $(P=0.001$; Fig. 1D). At 3 weeks, PGX + S/MET had the lowest HbA1c which was significantly different from $\mathrm{C}$ and S/MET and at 6 weeks, PGX + S/MET was lower than all other treatments except PGX + MET. PGX alone was similar to MET alone in reducing HbA1c.

\section{Glucose and regulators of feeding behavior during OGTT}

Similar to the weekly measures of glycemia, PGX + S/MET exhibited the lowest blood glucose concentration from 0 to $120 \mathrm{~min}$, which was significantly lower than all other

Table 1 Energy intake, body composition, and insulin sensitivity score of obese Zucker rats treated with MET or metformin/sitagliptin, alone or in combination with PGX for 6 weeks. Values are means \pm s.E.M., $n=10-11$

Treatment
Food intake (g/day)
Final body weight $(\mathrm{g})$
Total weight change $(\mathrm{g})$
Fat mass $(\mathrm{g})$
Lean mass $(\mathrm{g})$
Percent fat $(\%)$
Bone mineral content $(\mathrm{g})$
CISI, score

\begin{tabular}{c}
$c$ \\
\hline $25.5 \pm 0.6^{\mathrm{a}}$ \\
$459.7 \pm 8.0^{\mathrm{b}}$ \\
$134.5 \pm 4.9^{\mathrm{b}}$ \\
$243.2 \pm 5.0^{\mathrm{a}, \mathrm{b}}$ \\
$110.6 \pm 3.6$ \\
$66.9 \pm 0.9^{\mathrm{a}}$ \\
$9.9 \pm 0.1^{\mathrm{a}}$ \\
$0.15 \pm 0.03^{\mathrm{c}}$
\end{tabular}

\begin{tabular}{|c|c|c|}
\hline MET & S/MET & PGX \\
\hline $22.9 \pm 0.5^{b}$ & $23.5 \pm 0.8^{a, b}$ & $20.2 \pm 0.3^{c}$ \\
\hline $492.5 \pm 4.3^{a}$ & $458.4 \pm 8.9^{b}$ & $461.2 \pm 7.1^{b}$ \\
\hline $165.8 \pm 3.4^{a}$ & $132.8 \pm 5.6^{b}$ & $135.5 \pm 4.7^{b}$ \\
\hline $258.6 \pm 3.3^{a}$ & $234.5 \pm 3.6^{b}$ & $243.2 \pm 3.5^{a, b}$ \\
\hline $116.9 \pm 3.6$ & $111.3 \pm 3.0$ & $112.2 \pm 3.8$ \\
\hline $66.6 \pm 0.8^{a}$ & $67.1 \pm 0.8^{a}$ & $65.1 \pm 0.8^{a, b}$ \\
\hline $10.1 \pm 0.1^{\mathrm{a}}$ & $10.1 \pm 0.2^{\mathrm{a}}$ & $9.8 \pm 0.1^{\mathrm{a}}$ \\
\hline $0.09 \pm 0.01$ & ${ }^{c} 0.15 \pm 0.02^{c}$ & $0.12 \pm 0.02^{\mathrm{C}}$ \\
\hline
\end{tabular}

\begin{tabular}{l} 
PGX + MET \\
\hline $20.7 \pm 0.2^{\mathrm{c}}$ \\
$448.8 \pm 6.7^{\mathrm{b}, \mathrm{c}}$ \\
$120.9 \pm 3.1^{\mathrm{b}}$ \\
$226.9 \pm 4.4^{\mathrm{b}}$ \\
$112.2 \pm 3.0^{\mathrm{a}}$ \\
$65.9 \pm 0.4^{\mathrm{a}}$ \\
$9.4 \pm 0.2^{\mathrm{a}, \mathrm{b}}$ \\
$0.46 \pm 0.06^{\mathrm{b}}$
\end{tabular}

\begin{tabular}{c} 
PGX + S/MET \\
\hline $19.0 \pm 0.4^{c}$ \\
$426.8 \pm 7.3^{c}$ \\
$100.9 \pm 6.1^{c}$ \\
$201.9 \pm 6.7^{c}$ \\
$112.8 \pm 3.2$ \\
$62.2 \pm 1.1^{b}$ \\
$9.0 \pm 0.2^{b}$ \\
$0.86 \pm 0.15^{a}$ \\
\hline
\end{tabular}

\begin{tabular}{|cccc}
\hline \multicolumn{3}{l}{ Two-way ANOVA $\boldsymbol{P}$ values } \\
\cline { 1 - 1 } Diet & \multicolumn{1}{c}{ Drug } & Diet $\times$ Drug \\
0.001 & 0.009 & 0.008 \\
0.001 & 0.001 & 0.008 \\
0.001 & 0.001 & 0.001 \\
0.001 & 0.001 & 0.001 \\
0.846 & 0.615 & 0.564 \\
0.001 & 0.131 & 0.041 \\
0.001 & 0.209 & 0.013 \\
0.001 & 0.001 & 0.001
\end{tabular}

Labeled means without a common letter differ, $P<0.05$. C, control; MET, metformin; S/MET, sitagliptin/metformin; PGX, PolyGlycopleX.

http://joe.endocrinology-journals.org DOI: 10.1530/JOE-13-0484
() 2014 Society for Endocrinology Printed in Great Britain
Published by Bioscientifica Ltd. 

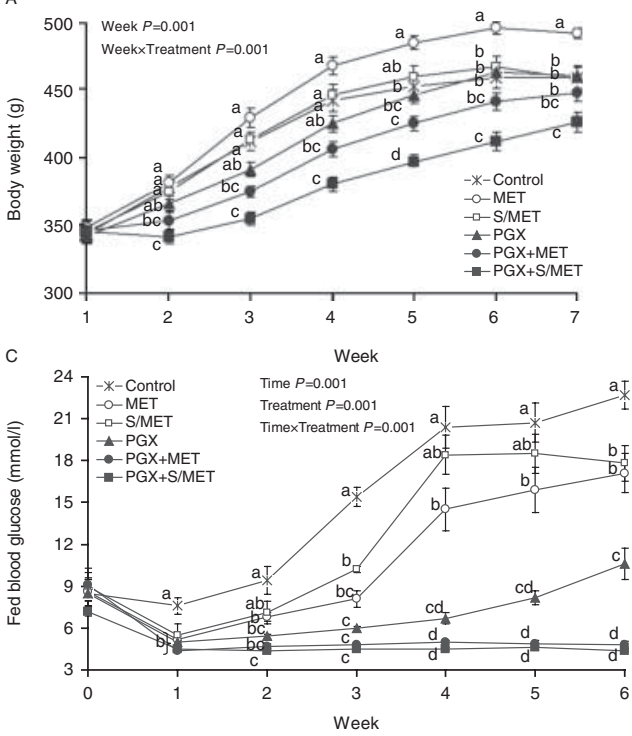
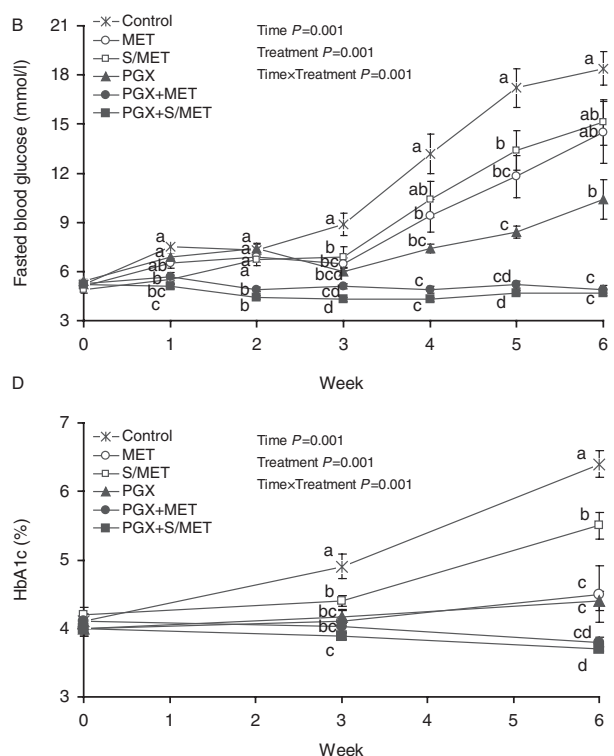

Figure 1

(A) Body weight, weekly fasted (B), and fed (C) blood glucose and HbA1c (D) of obese Zucker rats treated with metformin or metformin/sitagliptin, alone or in combination with PGX for 6 weeks. Values are mean \pm s.E.M.,

groups except PGX + MET $(P<0.05$; Fig. $2 \mathrm{~A})$. As monotherapies, PGX, MET, and S/MET all reduced blood glucose concentrations compared with $\mathrm{C}$ at 10, 20, 30, 60, and $120 \mathrm{~min}$. Throughout the OGTT, MET had higher insulin than C, PGX + MET, and PGX +S/MET (Fig. 2B). At the end $n=11$. Labeled means at a time without a common letter differ, $P<0.05$. C, control; MET, metformin; S/MET, sitagliptin/metformin; PGX, PolyGlycopleX.

of the OGTT, PGX also had higher insulin than C, PGX + MET, and PGX +S/MET. GLP1 concentrations were higher with $\mathrm{PGX}+\mathrm{S} / \mathrm{MET}$ than all other groups at $0,30,60$, and $90 \mathrm{~min}$ ( $P=0.001$; Fig. 2C). Rats fed PGX also had significantly higher PYY compared with $\mathrm{C}$, MET, S/MET,
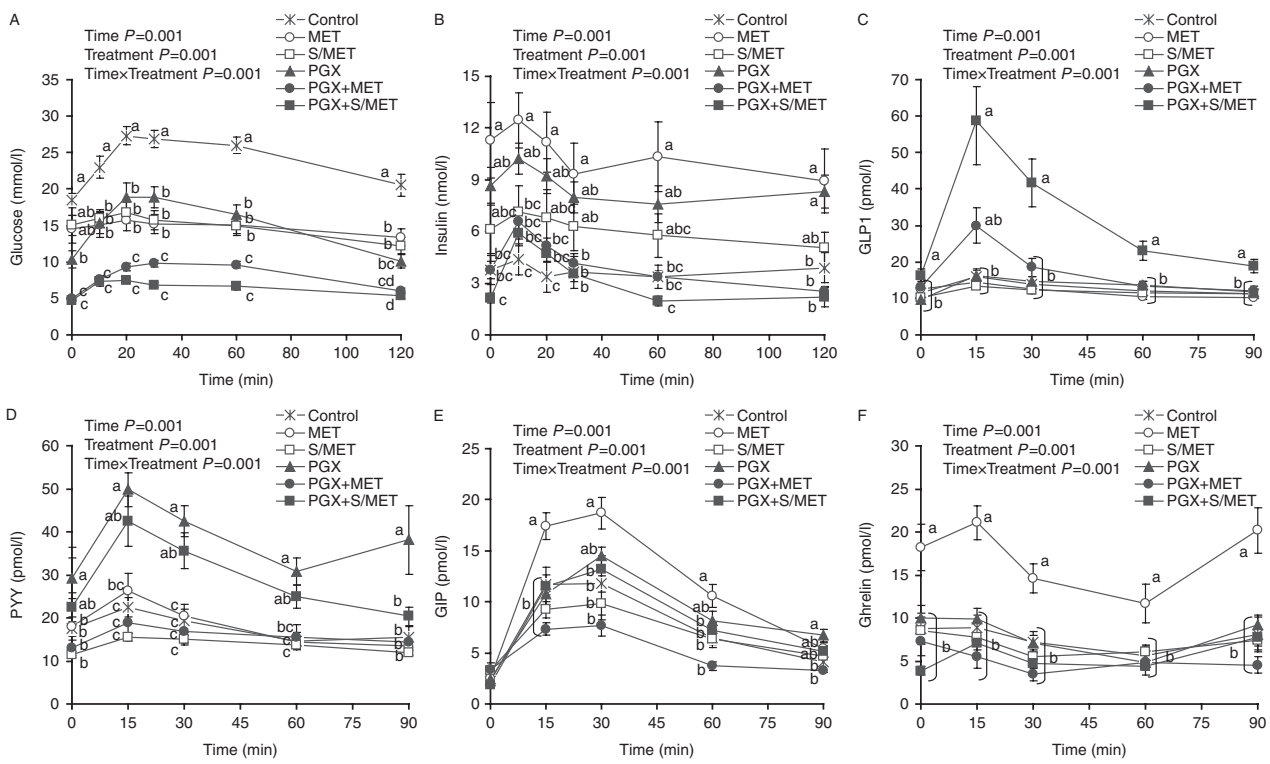

Figure 2

Blood glucose (A) and plasma insulin (B), GLP1 (C), PYY (D), GIP (E), and ghrelin (F) of obese Zucker rats during an OGTT. Values are mean \pm s.E.M., $n=10-11$. Labeled means at a time without a common letter differ, $P<0.05$.
C, control; GIP, glucose-dependent insulinotropic polypeptide; GLP1, glucagon-like peptide-1; MET, metformin; S/MET, sitagliptin/metformin; PGX, PolyGlycopleX. 
and PGX + MET at all time points (Fig. 2D). At $15 \mathrm{~min}$, MET had significantly higher GIP than all other groups and significantly higher GIP at 30 and 60 min compared with all groups except PGX (Fig. 2E). Ghrelin was higher with MET compared with all other groups throughout the entire OGTT (Fig. 2F). The CISI was significantly affected by diet $(P=0.001)$, drug $(P=0.001)$, and their interaction $(P=0.001)$, wherein PGX $+S /$ MET had the highest score which was significantly different from all other groups. AUC for glucose and all regulators of eating behavior is provided in Supplementary Table 1, see section on supplementary data given at the end of this article.

\section{Changes in DPP4 activity and expression}

Diet $(P=0.001)$, drug $(P=0.001)$, and their interaction $(P=0.001)$ affected DPP4 activity measured in plasma and kidney lysate (Fig. 3A). Plasma DPP4 activity was lower in PGX, S/MET, PGX+MET, and PGX+S/MET compared with $C$ and MET $(P<0.003)$, and S/MET and PGX +S/MET were lower than all other groups except PGX + MET $(P<0.02)$. In the kidney, PGX + MET and PGX + S/MET had significantly lower DPP4 activity than all other groups. Dpp4 mRNA levels were influenced by the interaction of diet and drug in the liver $(P=0.011)$ and ileum $(P=0.001$; Fig. 3B). No post hoc differences were revealed for the liver, but ileal Dpp4 mRNA levels were significantly higher in $\mathrm{C}$ and MET compared with all other groups $(P=0.01)$. S/MET had the lowest ileal $D p p 4$ mRNA levels which was significantly lower than C, MET, and PGX + MET but not PGX or PGX +S/MET.

\section{Pancreatic immunohistochemistry}

The insulin-immunoreactive area was higher in PGX + S/MET compared with all other groups while PGX + MET was higher than C, MET, S/MET, and PGX alone (Fig. 4A). Islet hypertrophy was higher in MET compared with PGX + MET ( $P=0.03$; Fig. 4B). Islet degeneration, where higher scores represent greater degeneration, was lowest in PGX + MET which was significantly lower than all other groups, while $\mathrm{PGX}+\mathrm{S} / \mathrm{MET}$ was significantly lower than $\mathrm{C}$ and PGX alone (Fig. 4C).

\section{Changes in hepatic histopathology and biomarkers}

All rats treated with PGX alone or in combination with MET and S/MET had reduced total cholesterol compared with C, MET, and S/MET (Table 2). In the liver, macrovesicular lipidosis was affected by the interaction of diet and
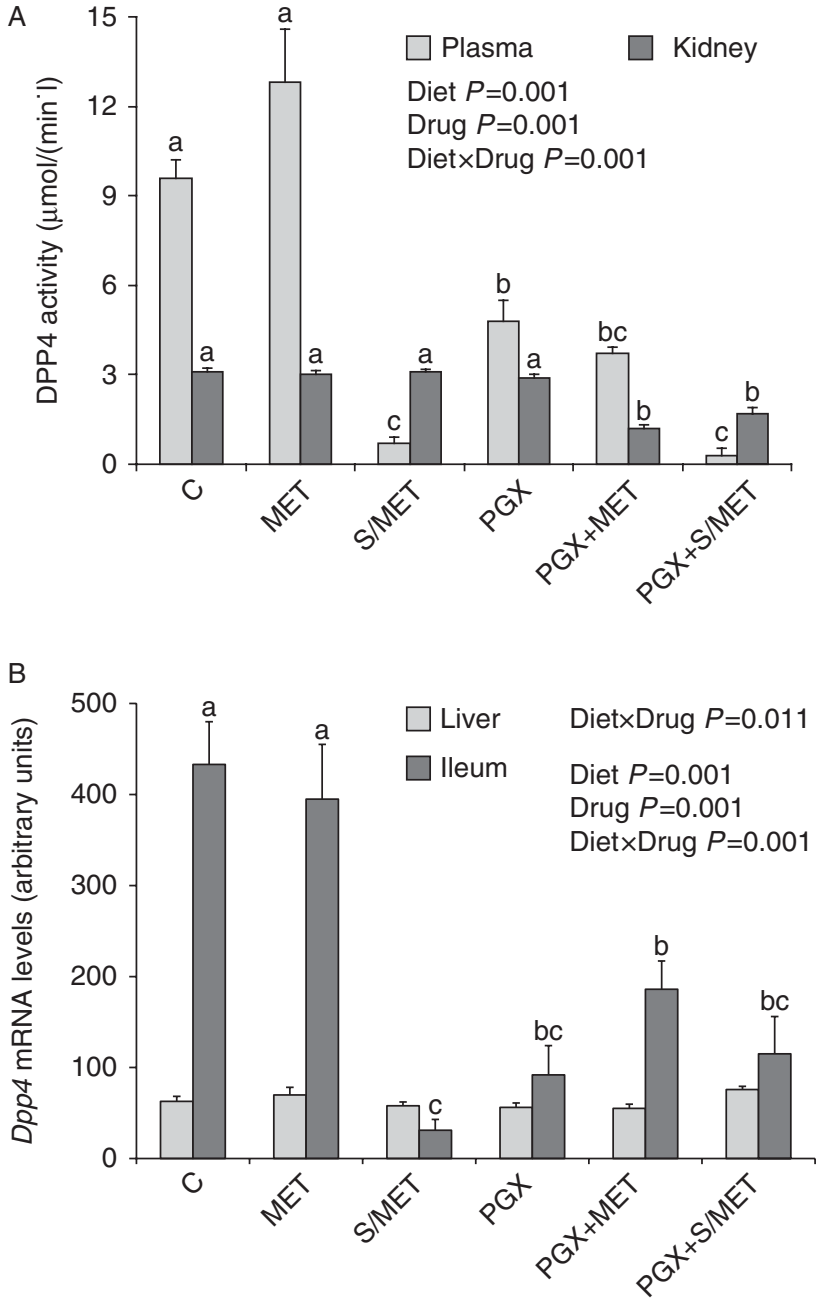

Figure 3

DPP4 activity in plasma and kidney (A) and Dpp4 mRNA levels in liver and ileum (B) of obese Zucker rats treated with MET or metformin/sitagliptin, alone or in combination with PGX for 6 weeks. DPP4 activity is expressed as amount (nmol) of AMC cleaved per minute per milliliter. Values are mean \pm s.E.M., $n=10-11$. Labeled means without a common letter differ, $P<0.05$. C, control; MET, metformin; S/MET, sitagliptin/metformin; PGX, PolyGlycopleX.

drug $(P=0.001)$, wherein S/MET alone had the highest score but when combined with PGX had the lowest and was significantly different compared with MET and S/MET alone (Table 2). Microvesicular lipidosis was significantly lower in PGX vs $\mathrm{C}$, MET and S/MET $(P=0.001)$ while $\mathrm{PGX}+\mathrm{S} / \mathrm{MET}$ was significantly lower than PGX but not different from PGX + MET. Serum alkaline phosphatase was independently affected by diet $(P=0.001)$ and drug $(P=0.001)$, wherein PGX was lower than cellulose and MET and S/MET were lower than vehicle.

Published by Bioscientifica Ltd. 

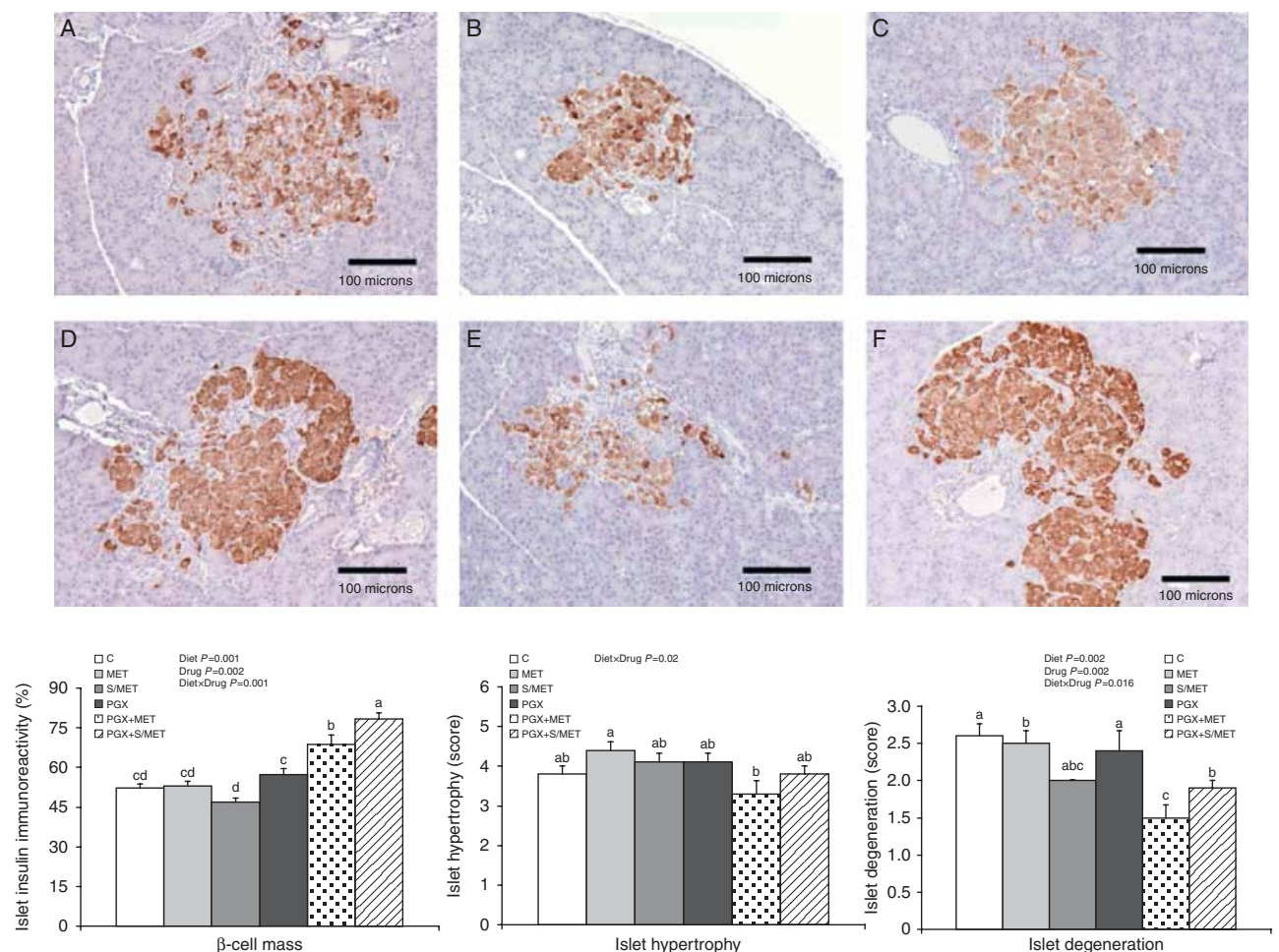

\section{Figure 4}

Photomicrographs of pancreas of obese Zucker rats treated with MET or metformin/sitagliptin, alone or in combination with PGX for 6 weeks. Photographs were selected as representative of the respective treatments: (A) C; (B) MET; (C) S/MET; (D) PGX; (E) MET+PGX; (F) S/MET+PGX. The bars are $100 \mu \mathrm{m}$. The brown-stained tissue is positive for insulin-containing cells

\section{Changes in gut microbiota}

Bacteroides abundance was significantly higher in rats treated with S/MET and C compared with MET, PGX, and $\mathrm{PGX}+\mathrm{S} / \mathrm{MET}(P=0.001$; Table 3$)$. All treatments lowered Clostridium coccoides compared with $\mathrm{C}(P<0.02)$. $C$. coccoides were lowest in $\mathrm{PGX}+\mathrm{S} / \mathrm{MET}$-treated rats, which was significantly lower than S/MET alone but not within the pancreas. $\beta$-cell mass, islet hypertrophy, and islet degeneration are presented graphically below the photomicrographs. Values are mean \pm S.E.M., $n=10-11$. Labeled means without a common letter differ, $P<0.05$. C, control; MET, metformin; S/MET, sitagliptin/metformin; PGX, PolyGlycopleX.

PGX alone. Bifidobacterium were very low across all groups. Significantly higher bifidobacteria were seen in MET and PGX compared with C, S/MET, and PGX+MET. Enterobacteriaceae were significantly higher in PGX compared with all other groups $(P<0.001)$. Independently, diet and drug influenced Clostridium leptum with cellulose higher than PGX and MET higher than vehicle and S/MET.

Table 2 Total cholesterol concentration and hepatic histology in obese Zucker rats treated with MET or metformin/sitagliptin, alone or in combination with PGX for 6 weeks. Values are means \pm s.E.M., $n=10$

\begin{tabular}{|c|c|c|c|c|c|c|c|c|c|}
\hline & \multirow[b]{2}{*}{ C } & \multirow[b]{2}{*}{ MET } & \multirow[b]{2}{*}{ S/MET } & \multirow[b]{2}{*}{ PGX } & \multirow[b]{2}{*}{ PGX + MET } & \multirow[b]{2}{*}{ PGX + S/MET } & \multicolumn{3}{|c|}{ Two-way ANOVA $P$ values } \\
\hline & & & & & & & Diet & Drug & Diet $\times$ Drug \\
\hline Total cholesterol (mmol/l) & $4.8 \pm 0.4^{b}$ & $7.6 \pm 0.4^{a}$ & $7.3 \pm 0.5^{a}$ & $3.5 \pm 0.1^{c}$ & $3.0 \pm 0.2^{c}$ & $3.2 \pm 0.1^{c}$ & 0.001 & 0.001 & 0.001 \\
\hline Macrovesicular lipidosis, score & $1.0 \pm 0.1^{a, b, c}$ & $1.2 \pm 0.1^{\mathrm{a}, \mathrm{b}}$ & $1.6 \pm 0.2^{a}$ & $0.8 \pm 0.1^{b, c}$ & $0.8 \pm 0.2^{b, c}$ & $0.4 \pm 0.2^{c}$ & 0.001 & 0.768 & 0.006 \\
\hline Microvesicular lipidosis, score & $3.4 \pm 0.3^{a}$ & $3.8 \pm 0.2^{a}$ & $3.6 \pm 0.3^{a}$ & $2.0 \pm 0.3^{b}$ & $1.2 \pm 0.2^{b, c}$ & $1.0 \pm 0.2^{c}$ & 0.001 & 0.246 & 0.018 \\
\hline Alkaline phosphatase (IU/l) & $290 \pm 36$ & $182 \pm 14$ & $174 \pm 9$ & $165 \pm 14$ & $103 \pm 6$ & $90 \pm 5$ & 0.001 & 0.001 & 0.363 \\
\hline ALT (IU/I) & $118 \pm 13$ & $95 \pm 17$ & $98 \pm 17$ & $106 \pm 39$ & $79 \pm 6$ & $68 \pm 6$ & 0.242 & 0.305 & 0.893 \\
\hline AST (IU/I) & $130 \pm 17$ & $103 \pm 13$ & $117 \pm 27$ & $161 \pm 56$ & $89 \pm 4$ & $98 \pm 8$ & 0.969 & 0.177 & 0.591 \\
\hline
\end{tabular}

Labeled means without a common letter differ, $P<0.05$. ALT, alanine aminotransferase; AST, aspartate aminotransferase; $C$, control; MET, metformin; S/MET, sitagliptin/metformin; PGX, PolyGlycopleX.

http://joe.endocrinology-journals.org DOI: 10.1530/JOE-13-0484
(C) 2014 Society for Endocrinology Printed in Great Britain
Published by Bioscientifica Ltd 


\section{Markers of intestinal permeability}

Serum LPS was significantly lower in PGX alone vs all other treatments except PGX + S/MET ( $P=0.001$; Fig. $5 \mathrm{~A}$ ). Expression of genes involved in gut permeability, ZO1, occludin, and proglucagon, were all significantly affected by drug $(P<0.027)$ but not diet with $S /$ MET resulting in lower mRNA levels for all genes compared with MET and vehicle (Fig. 5B, C, and D).

\section{Discussion}

Effective management of obesity and type 2 diabetes requires a multifaceted approach that ideally combines pharmacological treatments with dietary interventions that augment their actions (Farag \& Gaballa 2011). Dietary recommendations for the management of diabetes encourage individuals at risk for or diagnosed with diabetes to achieve dietary fiber intake at least at the level suggested for the general population (American Diabetes Association et al. 2008). Viscous dietary fiber, in particular, has been shown to slow glucose absorption from the small intestine and may be particularly relevant (Vuksan et al. 2009, Babio et al. 2010). In addition to lifestyle modification, many newly diagnosed type 2 diabetes patients are prescribed MET as a first-line antihyperglycemic agent (Papanas et al. 2009). Newer diabetes medications including the DPP4 inhibitor sitagliptin have been approved for use in conjunction with MET (Fass \& Gershman 2013). Our findings suggest that the actions of these medications can be augmented with the functional dietary fiber PGX.

The most striking finding of this study is that PGX + S/MET and PGX + MET delay the progression of diabetes in ZDF rats. Overt hyperglycemia typically develops in the ZDF rat by 10-12 weeks of age (Peterson et al. 1990). Indeed at 15 weeks of age and following 6 weeks of treatment, the rats treated with the combination therapies remained normoglycemic while all other groups progressed to full blown diabetes based on a postprandial hyperglycemia criteria of $>11.1 \mathrm{mmol} / \mathrm{l}$ and fasting criteria of $>7.1 \mathrm{mmol} / \mathrm{l}$. Interestingly, the PGX alone group maintained lower fed and fasted glucose concentrations throughout the 6 weeks compared with control and the two drug monotherapies but did eventually develop diabetes by the end of the study, suggesting that this functional fiber worked as well, if not slightly better than currently approved diabetes medications in lowering glycemia in this model at the doses selected. In addition to weekly fasted and fed blood glucose measurements, we also assessed HbA1c. Following the demonstration by two

Published by Bioscientifica Ltd. http://joe.endocrinology-journals.org DOI: 10.1530/JOE-13-0484
(๑) 2014 Society for Endocrinology Printed in Great Britain 

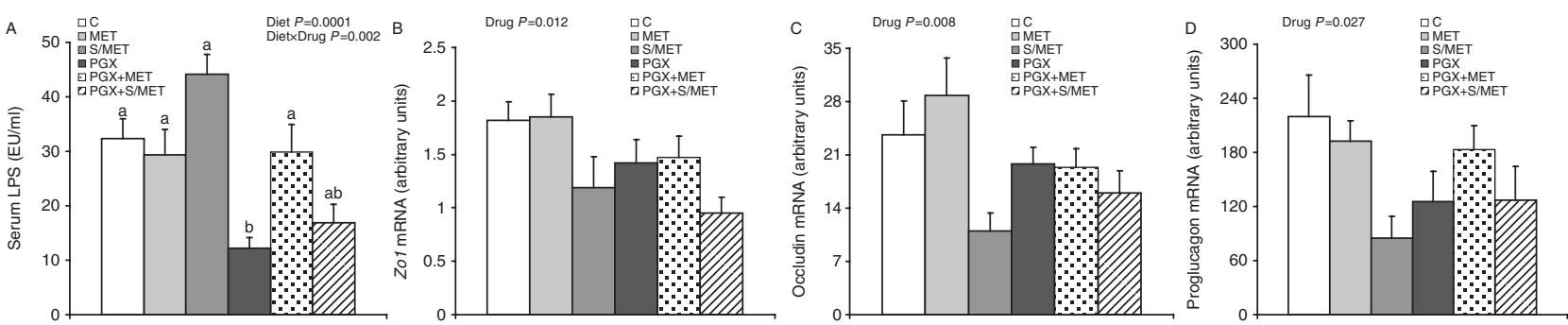

Figure 5

Serum LPS (A) and mRNA levels of Zo1 (B), occludin - OCLN (C), and proglucagon (D) of obese Zucker rats treated with MET or metformin/ sitagliptin, alone, or in combination with PGX for 6 weeks. Values are

landmark studies in the 1990s (DCCT Research Group 1993, UK Prospective Diabetes Study (UKPDS) Group 1998) that mean glycemia measured as HbA1c is directly related to diabetes complications, this outcome has been widely used as an indicator of long-term glycemia. PGX + S/MET maintained the lowest HbA1c throughout the study and although PGX + MET had comparable numerical values, at week 6 they were not statistically different from PGX alone and MET alone. Finally, PGX +S/MET and PGX + MET had lower glucose concentrations than all other groups throughout a 120 min OGTT.

We examined several potential mechanisms by which the improvements in glycemia might take place. Firstly, changes in weight gain and body composition could explain some of the improvements. Rats treated with PGX + S/MET had the lowest weight gain and fat mass; and comparable lean mass. Skeletal muscle is a major site for glucose disposal in the body (Irvine \& Taylor 2009) and by maintaining lean mass in the context of reduced fat mass, a reduction in insulin resistance may have occurred in these rats. Adipose tissue mass, and perhaps more importantly the inflammatory cytokines released from adipose tissue, have been implicated in insulin resistance (Gutierrez et al. 2009). Although we did not perform euglycemic hyperinsulinemic clamps to assess insulin sensitivity directly, we do have indirect indicators of improved insulin sensitivity. Using CISI as a surrogate marker of insulin sensitivity, we confirm that $\mathrm{PGX}+\mathrm{S} / \mathrm{MET}$ was associated with the greatest degree of insulin sensitivity which was significantly greater than all other groups. The potential of PGX to reduce inflammation associated with increased adiposity has recently been demonstrated in Japanese adults with abdominal obesity, consuming $15 \mathrm{~g}$ /day of PGX vs placebo (Reimer et al. 2013).

Within the pancreas, there were histological changes that support the attenuation in diabetes with the

mean \pm s.E.M., $n=10$. Labeled means at a time without a common letter differ, $P<0.05$. C, control; MET, metformin; S/MET, sitagliptin/metformin; PGX, PolyGlycopleX.

PGX $+\mathrm{S} / \mathrm{MET}$ treatment. $\beta$-cell mass is reduced by as much as $70 \%$ in individuals with type 2 diabetes compared with nondiabetic controls (Weir \& Bonner-Weir 2013). The precise cause of the reduced $\beta$-cell mass in type 2 diabetes is not known but likely involves a combination of oxidative stress, amyloid deposits, endoplasmic reticulum stress, and $\beta$-cell dedifferentiation (Weir \& Bonner-Weir 2013). In the current study, rats treated with PGX + S/MET displayed the highest $\beta$-cell mass. Interestingly, $\beta$-cell mass was lowest with S/MET but when combined with PGX, resulted in $\beta$-cell mass that was significantly higher than all other treatments which may have clinical relevance. While $\beta$-cell hypertrophy in the PGX + S/MET rats did not differ from the other treatments, its degeneration was significantly lower than PGX alone and control. Augmentation of $\beta$-cell function with S/MET has recently been shown in patients with type 2 diabetes (Solis-Herrara et al. 2013), which appears to be even further enhanced in our model with PGX. While interest in interventions to restore $\beta$-cell mass in type 2 diabetes, such as pancreas transplant (Nath et al. 2005) and drugs that stimulate $\beta$-cell regeneration (Halban et al. 2010) continues to increase, our findings would suggest that optimizing drug/diet combinations may provide greater success than drug targets considered in isolation.

There was a marked and sustained increase in active GLP1 with PGX +S/MET that was higher than all monotherapies throughout the OGTT. In humans, sitagliptin and S/MET increase GLP1 to a greater extent than placebo or MET alone (Solis-Herrara et al. 2013). Changes in DPP4 activity and Dpp4 mRNA levels may provide partial insights into the differences in the observed active GLP1 concentrations. DPP4 is a serine protease that inactivates polypeptides such as GLP1 and is expressed on the surface of various types of cells, including the small intestine, kidney, liver, and in a soluble form in plasma (Kirino et al. 2009). While DPP4 activity in the plasma of

Published by Bioscientifica Ltd. 
S/MET and PGX + S/MET rats did not differ, there was a significant reduction in DPP4 activity in the kidney of PGX + S/MET rats compared with S/MET. While it is not clear whether DPP4 activity plays a role in the onset or progression of diabetes, there is some evidence to suggest that inhibiting DPP4 with sitagliptin may exert additional actions at the level of the L cell by acting as a GLP1 secretagogue (Sangle et al. 2012). The combination of S/MET may augment endogenous GLP1 secretion given the demonstration by Mulherin et al. (2011) that MET stimulates GLP1 release in vivo through a mechanism relying on both muscarinic and gastrin-releasing peptide receptor-dependent pathways but not inhibition of DPP4 activity. This is consistent with our data showing no reduction in DPP4 activity or expression in rats treated with MET compared with control rats.

In addition to the increase in GLP1 seen with PGX+ S/MET, greater PYY response with PGX may also explain the reduction in food intake seen in all groups consuming PGX. Other soluble and fermentable fibers, such as oligofructose and insulin, have also been shown to increase PYY and blunt energy intake (Parnell \& Reimer 2009, Reimer et al. 2012b). Interestingly, ghrelin did not show the characteristic decline following the glucose load which is consistent with another model lacking a functional leptin receptor, the JCR:LA cp rat, where ghrelin declines in lean $(+/$ ?) rats but not obese $(c p / c p)$ rats (Parnell \& Reimer 2012).

Gut microbiota have been implicated in the development and maintenance of obesity in part through a contribution to low-grade inflammation or metabolic endotoxemia (Cani et al. 2012). We assessed serum lipopolysaccharide (LPS) as a marker of metabolic endotoxemia in our rats and showed that PGX alone results in the lowest levels of circulating LPS which was significantly lower than all other treatments except PGX+S/MET. Because LPS leaks into circulation via a compromised gut barrier (Cani et al. 2008, 2009), we also measured the expression of tight junction proteins in the ileum and demonstrated that ZO1 and occludin were affected by the drugs but not diet with S/MET, resulting in lower mRNA levels for all genes compared with MET and vehicle. Changes in barrier function and other host metabolic responses can occur in response to an alteration in the composition of the microbiota (Cani et al. 2008). Obesity has been characterized by an increase in the proportion of Firmicutes and reduction in Bacteroidetes (Ley et al. 2006), although not unanimously (Zhang et al. 2009). All treatments in our study reduced $C$. coccoides, a member of the Firmicutes phylum. The greatest reduction was seen in rats treated with $\mathrm{PGX}+\mathrm{S} / \mathrm{MET}$. We also saw a marked increase in Enterobacteriaceae with PGX. The significance of this shift is perhaps made clear by the findings of Zhang et al. (2009) who found that gastric bypass surgery markedly altered gut microbiota, most notably by a large increase in Gammaproteobacteria, members of the family Enterobacteriaceae, and a decrease in Firmicutes. Gastric bypass surgery, by design, results in the presentation of nutrients to more distal segments of the intestine. It is plausible that PGX, a functional fiber with a level of viscosity that is higher than any currently known individual polysaccharide, could create a luminal environment where nutrients are absorbed more distally. It is also plausible that the end-products of microbial fermentation of PGX, short-chain fatty acids (SCFA), affect the composition of gut microbiota in these rats and the secretion of gut satiety hormones (Wichmann et al. 2013). We have recently demonstrated ( $\mathrm{R}$ A Reimer, A J H Maathuis, K Venema, M R Lyon, R J Gahler and S Wood 2013, unpublished observations) that PGX is fermented by colonic microbiota in a dynamic, computer-controlled in vitro system simulating the conditions in the proximal large intestine (TIM2; Minekus et al. 1999). Given that fermentation of fibers can improve gut barrier function (Lappi et al. 2013), it is also possible that the reduced serum LPS noted in PGX-fed rats is due to reduced gut permeability and translocation of LPS into the circulation.

In this study, we were able to confirm the previously demonstrated reduction in total cholesterol with PGX (Grover et al. 2011a,b, Reimer et al. 2012a) which could be due to interruption of enterohepatic bile acid circulation, increases in the rate-limiting enzyme in the synthesis of bile acid from cholesterol (cholesterol-7- $\alpha$-hydroxylase), and production of SCFA (Babio et al. 2010). In addition, macro- and microvesicular lipidosis was reduced with PGX and in the case of microvesicular lipidosis reduced even further when combined with S/MET. Hepatic steatosis is the first hit in a cascade of non-alcoholic fatty liver disease that can progress to fibrosis and end-stage liver disease (Parnell et al. 2012). Given the recent demonstration that sitagliptin is able to inhibit liver fibrosis in rats (Kaji et al. 2013), there may be potential for a dietary compound such as PGX to provide additional benefit in chronic liver disease.

Effective management of obesity and type 2 diabetes requires an integrated approach that considers patient characteristics and available pharmacological options (Stein et al. 2013). It is common to use a combination of medications to optimize glycemic control and patient outcomes in the context of metabolic disease. The impact

Published by Bioscientifica Ltd. 
that lifestyle, and specifically dietary factors, might have on the action of those medications has received much less attention. Herein, we demonstrate that the actions of S/MET and to a similar but slightly lesser extent, MET are enhanced when they are administered with the functional fiber PGX. The most notable action is the attenuation in diabetes in the fatty Zucker rat, a finding that may have implications not only for the treatment of type 2 diabetes but also for the conversion of impaired glucose tolerance into full blown diabetes.

\section{Supplementary data}

This is linked to the online version of the paper at http://dx.doi.org/10.1530/ JOE-13-0484.

\section{Declaration of interest}

$R$ A $R$ receives consulting fees from InovoBiologic, Inc. and received financial support for the preparation of this manuscript. G J G and $L K$ received funding from InovoBiologic, Inc. to perform this study and have no financial interest in PGX. R J G is the owner of the Factors Group of Nutritional Companies, which retains an interest in PGX. M R L receives consulting fees from the Factors Group of Companies and has no financial interest in PGX. S W receives consulting fees from InovoBiologic, Inc. and has no financial interest in PGX.

\section{Funding}

This project was funded by InovoBiologic, Inc., Calgary, Canada.

\section{Author contribution statement}

All authors designed research; G J G, L K, and R A R conducted research; R A R, G J G, and L K analyzed data; R A R wrote the paper; R A R and S W had primary responsibility for final content. All authors read and approved the final version of the paper.

\section{Acknowledgements}

The authors thank Kristine Lee (University of Calgary), Joan Wicks (Alizee), Sue Shapses (Rutgers University) Jamie Boulet, Leia Rispoli, Harry Maselli, and Jessica Beyenhof (Product Safety Labs) for their technical assistance with this work. PGX and PolyGlycopleX are registered trademarks of InovoBiologic, Inc., Canada. All other trademarks belong to their respective owners.

\section{References}

Ahren B 2007 Dipeptidyl peptidase-4 inhibitors: clinical data and clinical implications. Diabetes Care 30 1344-1350. (doi:10.2337/dc07-0233)

American Diabetes Association, Bantle JP, Wylie-Rosett J, Albright AL, Aprovian CM, Clark NG, Franz MJ, Hoogwerf BJ, Lichtenstein AH, Mayer-Davis E et al. 2008 Nutrition recommendations and interventions for diabetes: a position statement of the American Diabetes Association. Diabetes Care 31(Suppl 1) S61-S78. (doi:10.2337/ dc08-S061)
Anderson JW, Jones AE \& Riddel-Mason S 1994 Ten different dietary fibers have significantly different effects on serum and liver lipids of cholesterol-fed rats. Journal of Nutrition 124 78-83.

Aschner P, Kipnes MS, Lunceford JK, Sanchez M, Mickel C, WilliamsHerman DE \& Sitagliptin Study 021 Group 2006 Effect of the dipeptidyl peptidase-4 inhibitor sitagliptin as monotherapy on glycemic control in patients with type 2 diabetes. Diabetes Care 29 2632-2637. (doi:10.2337/dc06-0703)

Babio N, Balanza R, Basulto J, Bullo M \& Salas-Salvado J 2010 Dietary fibre: influence on body weight, glycemic control and plasma cholesterol profile. Nutrición Hospitalaria 25 327-340.

Bomhof MR, Saha DC, Reid DT, Paul HA \& Reimer RA 2013 Individual and combined effects of oligofructose and Bifidobacterium animalis on gut microbiota and glycemia in obese rats. Obesity [in press]. (doi:10.1002/ oby.20632)

Cani PD, Bibiloni R, Knauf C, Waget A, Neyrinck AM, Delzenne NM \& Burcelin R 2008 Changes in gut microbiota control metabolic endotoxemia-induced inflammation in high-fat diet-induced obesity and diabetes in mice. Diabetes 57 1470-1481. (doi:10.2337/db07-1403)

Cani PD, Possemiers S, Van de Wiele T, Guiot Y, Everard A, Rottier O, Geurts L, Naslain D, Neyrinck A, Lambert DM et al. 2009 Changes in gut microbiota control inflammation in obese mice through a mechanism involving GLP-2-driven improvement in gut permeability. Gut $\mathbf{5 8}$ 1091-1103. (doi:10.1136/gut.2008.165886)

Cani PD, Osto M, Geurts L \& Everard A 2012 Involvement of gut microbiota in the development of low-grade inflammation and type 2 diabetes associated with obesity. Gut Microbes 3 279-288. (doi:10.4161/ gmic.19625)

Charbonnel B, Karasik A, Liu J, Wu M, Meininger G \& Sitagliptin Study 020 Group 2006 Efficacy and safety of the dipeptidyl peptidase- 4 inhibitor sitagliptin added to ongoing metformin therapy in patients with type 2 diabetes inadequately controlled with metformin alone. Diabetes Care 29 2638-2643. (doi:10.2337/dc06-0706)

Chen B, Moore A, Escobedo LV, Koletsky MS, Hou D, Koletsky RJ \& Ernsberger P 2011 Sitagliptin lowers glucagon and improves glucose tolerance in prediabetic obese SHROB rats. Experimental Biology and Medicine 236 309-314. (doi:10.1258/ebm.2010.010161)

Chutkan R, Fahey G, Wright WL \& McRorie J 2012 Viscous versus nonviscous soluble fiber supplements: mechanisms and evidence for fiber-specific health benefits. Journal of the American Academy of Nurse Practitioners 24 476-487. (doi:10.1111/j.1745-7599.2012.00758.x)

Daousi C, Casson IF, Gill GV, MacFarlane IA, Wilding JPH \& Pinkney JH 2006 Prevalence of obesity in type 2 diabetes in secondary care: association with cardiovascular risk factors. Postgraduate Medical Journal 82 280-284. (doi:10.1136/pmj.2005.039032)

DCCT Research Group 1993 The effect of intensive treatment of diabetes on the development and progression of long term complications in insulin dependent diabetes mellitus. New England Journal of Medicine 329 977-986. (doi:10.1056/NEJM199309303291401)

Eller LK \& Reimer RA 2010 A high calcium, skim milk powder diet results in a lower fat mass in male, energy-restricted, obese rats more than a low calcium, casein or soy protein diet. Journal of Nutrition 140 1234-1241. (doi:10.3945/jn.109.119008)

Farag YM \& Gaballa MR 2011 Diabesity: an overview of a rising epidemic. Nephrology, Dialysis, Transplantation 26 28-35. (doi:10.1093/ndt/ gfq576)

Fass AD \& Gershman JA 2013 Efficacy and safety of dipeptidyl peptidase-4 inhibitors in combination with metformin. Advances in Therapy 30 337-353. (doi:10.1007/s12325-013-0023-6)

Franco M, Bilal U, Ordunez P, Benet M, Morejon A, Caballero B, Kennelly JF \& Cooper RS 2013 Population-wide weight loss and regain in relation to diabetes burden and cardiovascular mortality in Cuba 1980-2010: repeated cross sectional surveys and ecological comparison of secular trends. BMJ 346 f1515. (doi:10.1136/bmj.f1515)

Grover GJ, Koetzner L, Wicks J, Gahler R, Lyon MR, Reimer RA \& Wood S $2011 a$ Effects of the soluble fiber complex PolyGlycopleX on glucose 
homeostasis and body weight in young Zucker diabetic rats. Frontiers in Pharmacology 2 47. (doi:10.3389/fphar.2011.00047)

Grover GJ, Koetzner L, Wicks J, Gahler RJ, Lyon MR, Reimer RA \& Wood S $2011 b$ Effects of the soluble fiber complex PolyGlycopleX ${ }^{\circledR}$ (PGX $\left.{ }^{\circledR}\right)$ on glycemic control, insulin secretion, and GLP-1 levels in Zucker diabetic rats. Life Sciences 88 392-399. (doi:10.1016/ j.lfs.2010.11.014)

Gutierrez DA, Puglisi MJ \& Hasty AH 2009 Impact of increased adipose tissue mass on inflammation, insulin resistance, and dyslipidemia. Current Diabetes Reports 9 26-32. (doi:10.1007/s11892-009-0006-9)

Halban PA, German MS, Kahn SE \& Weir GC 2010 Current status of islet cell replacement and regeneration therapy. Journal of Clinical Endocrinology and Metabolism 95 1034-1043. (doi:10.1210/ jc.2009-1819)

Inzucchi SE 2002 Oral antihyperglycemic therapy for type 2 diabetes: scientific review. Journal of the American Medical Association 287 360-372. (doi:10.1001/jama.287.3.360)

Irvine C \& Taylor NF 2009 Progressive resistance exercise improves glycaemic control in people with type 2 diabetes mellitus: a systematic review. Australian Journal of Physiotherapy 55 237-246. (doi:10.1016/ S0004-9514(09)70003-0)

Kaji K, Yoshiji H, Ikenaka Y, Noguchi R, Aihara Y, Douhara A, Moriya K, Kawaratani H, Shirai Y, Yoshii J et al. 2013 Dipeptidyl peptidase-4 inhibitor attenuates hepatic fibrosis via suppression of activated hepatic stellate cell in rats. Journal of Gastroenterology [in press].

Kirino Y, Kamimoto T, Sata Y, Kawazoe K, Minakuchi K \& Nakahori Y 2009 Increased plasma dipeptidyl peptidase IV (DPP IV) activity and decreased DPP IV activity of visceral but not subcutaneous adipose tissue in impaired glucose tolerance rats induced by high-fat or high-sucrose diet. Biological \& Pharmaceutical Bulletin 32 463-467. (doi:10.1248/bpb.32.463)

Lappi J, Kolehmainen M, Mykkanen H \& Poutanen K 2013 Do large intestinal events explain the protective effects of whole grain foods against type 2 diabetes? Critical Reviews in Food Science and Nutrition 53 631-640. (doi:10.1080/10408398.2010.550388)

Ley RE, Turnbaugh PJ, Klein S \& Gordon JI 2006 Human gut microbes associated with obesity. Nature 444 1022-1023. (doi:10.1038/ 4441022a)

Maiztegui B, Borelli MI, Madrid VG, Del Zotto H, Raschia MA, Francini F, Massa ML, Flores LE, Rebolledo OR \& Gagliardino JJ 2011 Sitagliptin prevents the development of metabolic and hormonal disturbances, increased $\beta$-cell apoptosis and liver steatosis induced by a fructose-rich diet in normal rats. Clinical Science 120 73-80. (doi:10.1042/ CS20100372)

Minekus M, Smeets-Peeters M, Bernalier A, Marol-Bonnin S, Havenaar R, Marteau P, Alric M, Fonty G \& Huis in't Veld JH 1999 A computercontrolled system to simulate conditions of the large intestine with peristaltic mixing, water absorption and absorption of fermentation products. Applied Microbiology and Biotechnology 53 108-114. (doi:10.1007/s002530051622)

Mulherin AJ, Oh AH, Kim H, Grieco A, Lauffer LM \& Brubaker PL 2011 Mechanisms underlying metformin-induced secretion of glucagon-like peptide-1 from the intestinal L cell. Endocrinology 152 4610-4619. (doi:10.1210/en.2011-1485)

Nath DS, Gruessner AC, Kandaswarmy R, Gruessner RW, Sutherland DE \& Humar A 2005 Outcomes of pancreas transplants for patients with type 2 diabetes mellitus. Clinical Transplantation 19 792-797. (doi:10.1111/ j.1399-0012.2005.00423.x)

National Institutes of Health 1998 Clinical guidelines on the identification, evaluation, and treatment of overweight and obesity in adults. The evidence report. Obesity Research 6(Suppl) 51S-209S.

Nauck M, Meininger G, Sheng D, Terranella L, Stein PP \& Sitagliptin Study 024 Group 2007 Sitagliptin/Metformin (Janumet) as combination therapy in the treatment of type-2 diabetes mellitus. Diabetes, Obesity \& Metabolism 9 194-205. (doi:10.1111/j.1463-1326.2006.00704.x)
Papanas N, Maltezos E \& Mikhailidis D 2009 Metformin: diamonds are forever. Expert Opinion on Pharmacotherapy 10 2395-2397. (doi:10.1517/ 14656560903176453)

Parnell JA \& Reimer RA 2009 Weight loss during oligofructose supplementation is associated with decreased ghrelin and increased peptide YY in overweight and obese adults. American Journal of Clinical Nutrition 89 1751-1759. (doi:10.3945/ajcn.2009.27465)

Parnell JA \& Reimer RA 2012 Prebiotic fibres dose-dependently increase satiety hormones and alter Bacteroidetes and Firmicutes in lean and obese JCR:LA cp rats. British Journal of Nutrition 107 601-613. (doi:10.1017/S0007114511003163)

Parnell JA, Raman M, Rioux KP \& Reimer RA 2012 The potential role of prebiotic fibre for treatment and management of nonalcoholic fatty liver disease and associated obesity and insulin resistance. Liver International 32 701-711. (doi:10.1111/j.1478-3231. 2011.02730.x)

Peterson RG, Shaw WN, Neel M-A, Little LA \& Eichberg J 1990 Zucker diabetic fatty rat as a model of non-insulin dependent diabetes mellitus. ILAR News 32 16-19. (doi:10.1093/ilar.32.3.16)

Pyra KA, Saha DC \& Reimer RA 2012 Prebiotic fiber increases hepatic acetyl CoA carboxylase phosphorylation and suppresses glucose-dependent insulinotropic polypeptide secretion more effectively when used with metformin in obese rats. Journal of Nutrition 142 213-220. (doi:10.3945/ jn.111.147132)

Reimer RA, Grover GJ, Koetzner L, Gahler R, Juneja P, Lyon MR \& Wood S $2012 a$ Sitagliptin reduces hyperglycemia and increases satiety hormone secretion more effectively when used with a novel polysaccharide in obese Zucker rats. Journal of Nutrition 142 1812-1820. (doi:10.3945/ jn.112.163204)

Reimer RA, Maurer AD, Eller LK, Hallam MC, Shaykhutdinov R, Vogel HJ \& Weljie AM 2012b Satiety hormone and metabolomic response to an intermittent high energy diet differs in rats consuming long-term diets high in protein or prebiotic fiber. Journal of Proteome Research 11 4065-4074. (doi:10.1021/pr300487s)

Reimer RA, Yamaguchi H, Eller LK, Lyon MR, Gahler RJ, Kacinik V, Juneja P \& Wood S 2013 Changes in visceral adiposity and serum cholesterol with a novel viscous polysaccharide in Japanese adults with abdominal obesity. Obesity 21 E379-E387. (doi:10.1002/oby.20435)

Sangle GV, Lauffer LM, Grieco A, Iakoubov R \& Brubaker PL 2012 Novel biological action of the dipeptidylpeptidase-IV inhibitor, sitagliptin, as a glucagon-like peptide-1 secretagogue. Endocrinology 153 564-573. (doi:10.1210/en.2011-1732)

Scheen AJ \& Paquot N 2013 Metformin revisited: a critical review of the benefit-risk balance in at-risk patients with type 2 diabetes. Diabetes \& Metabolism 39 179-190. (doi:10.1016/j.diabet. 2013.02.006)

Shaw JE, Sicree RA \& Zimmet PZ 2010 Global estimates of the prevalence of diabetes for 2010 and 2030. Diabetes Research Clinical Practice 87 4-14. (doi:10.1016/j.diabres.2009.10.007)

Solis-Herrara C, Triplitt C, Garduno-Garcia JD, Adams J, DeFronzo RA \& Cersosimo E 2013 Mechanisms of glucose lowering of dipeptidyl peptidase-4 inhibitor sitagliptin when used alone or with metformin in type 2 diabetes: a double-tracer study. Diabetes Care 36 2756-2762. (doi:10.2337/dc12-2072)

Stein SA, Lamos EM \& Davis SN 2013 A review of the efficacy and safety of oral antidiabetic drugs. Expert Opinion on Drug Safety 12 153-175. (doi:10.1517/14740338.2013.752813)

St Onge EL, Miller S \& Clements E 2012 Sitagliptin/Metformin (Janumet) as combination therapy in the treatment of type- 2 diabetes mellitus. $P \& T$ 37 699-708.

UK Prospective Diabetes Study (UKPDS) Group 1998 Intensive bloodglucose control with sulphonylureas or insulin compared with conventional treatment and risk of complications in patients with type 2 diabetes (UKPDS 33). Lancet 352 837-851. (doi:10.1016/ S0140-6736(98)07019-6) http://joe.endocrinology-journals.org DOI: 10.1530/JOE-13-0484
() 2014 Society for Endocrinology Printed in Great Britain 
Vuksan V, Rogovik AL, Jovanovski E \& Jenkins AL 2009 Fiber facts: benefits and recommendations for individuals with type 2 diabetes. Current Diabetes Reports 9 405-411. (doi:10.1007/s11892-009-0062-1)

Weickert MO \& Pfeiffer AFH 2008 Metabolic effects of dietary fiber consumption and prevention of diabetes. Journal of Nutrition 138 439-442.

Weir GC \& Bonner-Weir S 2013 Islet $\beta$ cell mass in diabetes and how it relates to function, birth, and death. Annals of the New York Academy of Sciences 1281 92-105. (doi:10.1111/nyas.12031)
Wichmann A, Allahyar A, Greiner TU, Plovier H, Lunden GO, Larsson T, Drucker DJ, Delzenne NM, Cani PD \& Backhed F 2013 Microbial modulation of energy availability in the colon regulates intestinal transit. Cell Host \& Microbe 14 582-590. (doi:10.1016/j.chom. 2013.09.012)

Zhang H, DiBaise JK, Zuccolo A, Kudrna D, Braidotti M, Yu Y, Parameswaran P, Crowell MD, Wing R, Rittmann BE et al. 2009 Human gut microbiota in obesity and after gastric bypass. PNAS 106 2365-2237. (doi:10.1073/pnas.0812600106)

Received in final form 9 December 2013

Accepted 2 January 2014

Accepted Preprint published online 3 January 2014
Published by Bioscientifica Ltd. 